\title{
Arctic2k: Synthesizing paleoclimate data to assess Arctic climate change
}

\section{SAMI HANHIJÄRVI}

Department of Environmental Sciences, University of Helsinki, Finland; sami.hanhijarvi@helsinki.fi

The Arctic has witnessed increased warming in comparison to other parts of the globe. Due to this amplification, the Arctic is a key region for climate studies, and is potentially central in elucidating the processes that govern the $19^{\text {th }}$ and $20^{\text {th }}$ century global warming. The PAGES Arctic2k Working Group was initiated to research the climate of the Arctic region within the past 2000 years. The Working Group had its second meeting in San Francisco, which was attended by 10 participants.

To date, much of the Working Group's efforts have been focused on generating high quality, high-resolution proxy records from the Arctic region. At this meeting, a new Icelandic glacier proxy record was introduced in addition to a new type of ice cover proxy record. The group has also aspired to collect a comprehensive list of available records and information about their nature and quality. Figure 1 depicts the combined locations of proxy records used in recent multiproxy studies, as well as records available from the NOAA Paleoclimatology database.

The criteria for the inclusion of specific proxy records were thoroughly discussed and formulated to ensure selection of only high quality proxy records, to avoid swamping the collection and synthesis processes with low quality records. It was decided that the criteria and template for proxy metadata should be offered to other PAGES 2k Regional Groups, so that if adopted, the proxy lists of all $2 \mathrm{k}$ Regional Groups would be compatible and the collection efforts need not be replicated for a global synthesis.

The statistical problems of climate reconstructions were also discussed. The proxy records tend to be spatially clustered, which can cause overrepresentation of the clustered areas in the synthesis. Another problem discussed is that the proxy records do not directly record a certain climate parameter and transforming the proxy data to, for example, temperature is often not straightforward. Existing reconstruction methods were briefly listed and their assumptions were discussed.

The temporal uncertainty was identified as possibly the largest cause of uncertainty in proxy reconstructions. As annually

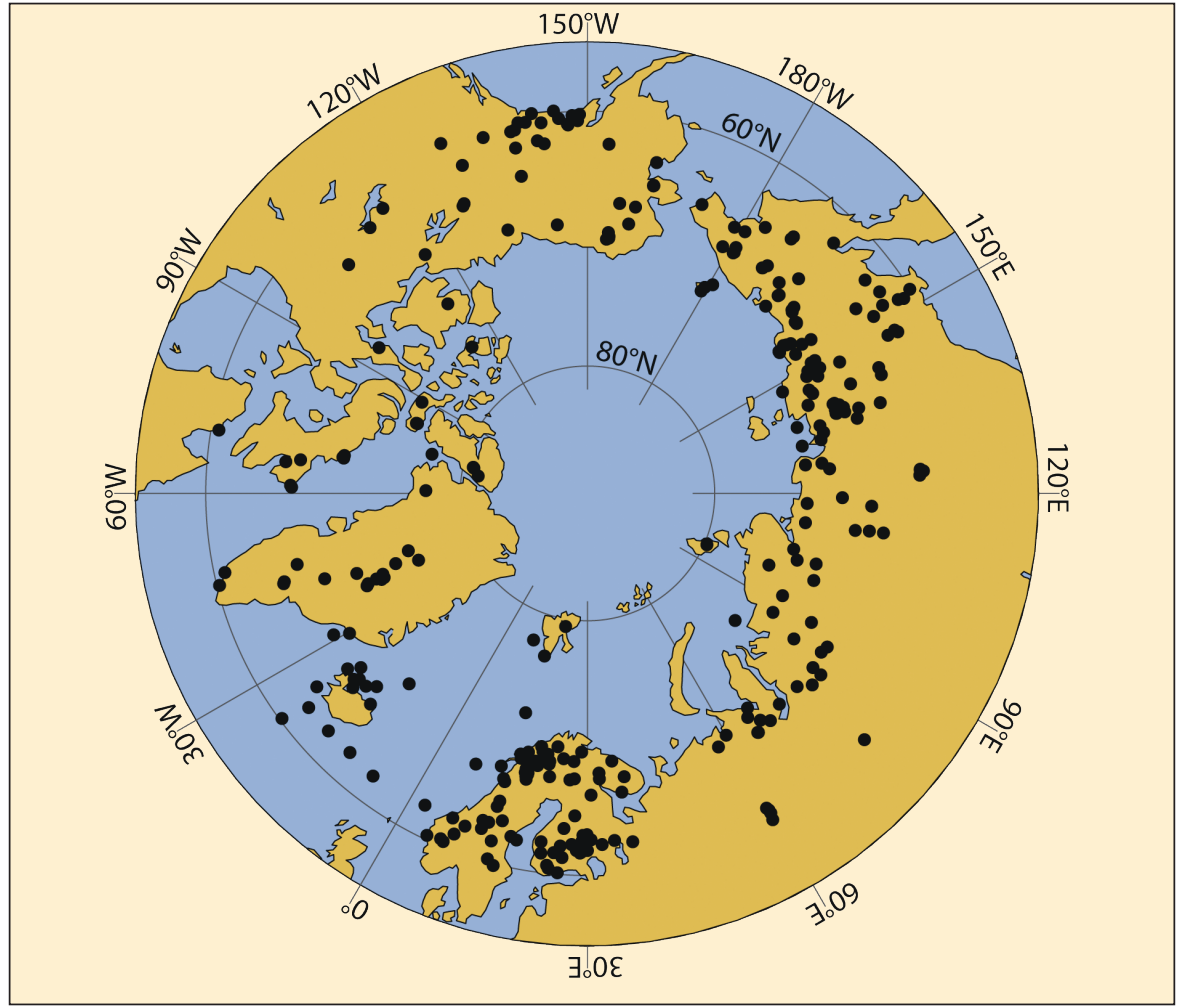

Figure 1: Spatial coverage of proxy records that extend back to 1500 AD in the Arctic. Proxy locations are a combination from Mann et al., 2008; Kaufman et al., 2009; Ljungqvist, 2010; Sundqvist et al., 2010; and from the NOAA Paleoclimatology database.

resolved proxies do not have the necessary temporal and spatial coverage, proxies with uncertain dates are necessary for the inference of climate parameters, especially before $1000 \mathrm{AD}$. The temporal uncertainty has to be accounted for in the overall uncertainty of climate reconstructions, which poses methodological problems.

A number of scientific questions emerged during the workshop, ranging from the spatiotemporal patterns of the Arctic climate to the utilization of the future synthesis produced by the Working Group. The questions were subdivided into four milestones that form the outline of future research. The first milestone involves inferring the spatial and temporal variability of the Arctic climate, and how they relate to the instrumental records of the recent past. The second milestone tackles the abrupt events recorded in the history of the Arctic, with special focus on the frequency of such events and to the possible thresholds that were exceeded before these events. The third milestone combines the knowledge of the two previous ones and seeks to answer questions about the long-term modes of the Arctic climate variability, and how much of the variability can be explained by internal adjustment of the climate system versus the external forcings (such as changes in solar irradiance and volcanic activity). The final milestone aims at involving people from the climate modeling community to use the obtained results to improve and enhance the climate models and to increase the accuracy of future predictions.

\section{References}

Kaufman, D.S., et al., 2009: Recent warming reverses Long-term arctic cooling, Science, 325 (5945): 1236-1239.

Ljungqvist, F.C., 2010: A new reconstruction of temperature variability in the extra-tropical Northern hemisphere during the last two millennia, Geografiska Annaler: Series A, Physical Geography, 92(3): 339-351.

Mann, M.E., Zhang, Z., Hughes, M.K., Bradley, R.S., Miller, S.K., Rutherford, S. and Ni, F., 2008: Proxy-based reconstructions of hemispheric and global surface temperature variations over the past two millennia, Proceedings of the National Academy of Sciences, 105(36): 1325-13257.

Sundqvist, H.S., Zhang, Q., Moberg, A., Holmgren, K., Körnich, H., Nilsson, J. and Brattström, G., 2010: Climate change between the mid and late Holocene in northern high latitudes - part 1: Survey of temperature and precipitation proxy data, Climate of the Past, 6(5): 591-608

Contributors of the IGBP PAGES/World Data Center for Paleoclimatology, NOAA/NCDC Paleoclimatology Program, Boulder, Colorado, USA. 